\begin{tabular}{|c|c|c|}
\hline 18 & $\begin{array}{c}\text { European Association for the } \\
\text { Development of Renewable Energies, Environment } \\
\text { and Power Quality (EA4EPQ) }\end{array}$ & $\begin{array}{l}\text { International Conference on Renewable Energies and Power Quality } \\
\text { (ICREPQ'12) } \\
\text { Santiago de Compostela (Spain), 28th to 30th March, } 2012\end{array}$ \\
\hline
\end{tabular}

\title{
Uncertainty Budget Analysis and its role in Microbial Fuel Cell Parameter Characterization
}

\author{
${ }^{1}$ M.C.J Andrews, ${ }^{1}$ D. P. Sharma, ${ }^{1}$ H.P.S. Missan \\ ${ }^{1}$ Department of Physics \\ University of the West Indies, St. Augustine, Trinidad (W.I.) \\ e-mail: miguel.andrews@my.uwi.edu,davinder.sharma@sta.uwi.edu, \\ harinder.missan@sta.uwi.edu
}

\begin{abstract}
Many renewable technologies are currently being investigated to reduce the world's dependence on greenhouse-gas emitting energy sources. This paper seeks to demonstrate how industrial metrological techniques may be employed in the evaluation of uncertainty of one of these techniques - the Microbial Fuel Cell. A description of how uncertainty analysis is evaluated in metrological laboratories for temperature measurement is presented, with the intention of applying the same technique to temperature measurements obtained when assessing microbial fuel cell performance. A JAVA-based temperature uncertainty budget calculator was also developed based on the assumptions used to perform the uncertainty analysis. This open-source application enables laboratories to compare uncertainties in their temperature measuring instruments. The Uncertainty Analysis is based on a method employed at an ISO/IEC 17025:2005 accredited Metrological Laboratory.
\end{abstract}

\section{Key Words}

Uncertainty, Industrial Metrology, Microbial Fuel Cells, Temperature Measurement

\section{Introduction}

The microbial fuel cell is an exciting new technology that has recently re-emerged on the research stage [1]. This device has provided the scientific and entrepreneurial communities with a product that possesses limitless research and commercial opportunities for the upcoming decade [2].

Microbial fuel cells generate electric current through a series of complex bio-electrochemical reactions between microorganisms, known as exoelectrogens, and a given substrate (the fuel) [3]. These bio- electrochemical reactions occur at the anode facilitating the generation of protons and electrons. The electrons are transported through the anode to the external circuit while the protons generated diffuse through a proton conducting membrane toward the cathode. The electrons and protons recombine with oxygen adsorbed on the cathode surface to form water, thus completing the process. The aforementioned steps enable microbial fuel cells to be used, in conjunction with existing waste water treatment operations, to facilitate widespread cogeneration and the production of clean water [4].

Uncertainty budget estimation, as outlined in the Guide to Uncertainty in Measurement and others [5] [6], is a tool that may be used to identify opportunities for improvement when measuring physical properties of microbial fuel cells. The uncertainty budget identifies the major sources of doubt in measurements as well as their relative effects on the derived quantity.

This paper seeks to derive uncertainty budgets for the fuel cell parameters outlined in [7]. The ${ }^{1}$ parameters, defined in the aforementioned paper, provide a common ground for researchers to compare microbial fuel cell performance. However, statement of these measurements in the absence of uncertainties makes true comparison of data between laboratories difficult. In addition, uncertainty budget derivation provides the experimenter with a systematic method for optimizing the measurement process and thus the reliability of the data published.

\footnotetext{
${ }^{1}$ These parameters are quantitative values that may be obtained by direct measurement or calculation.
} 


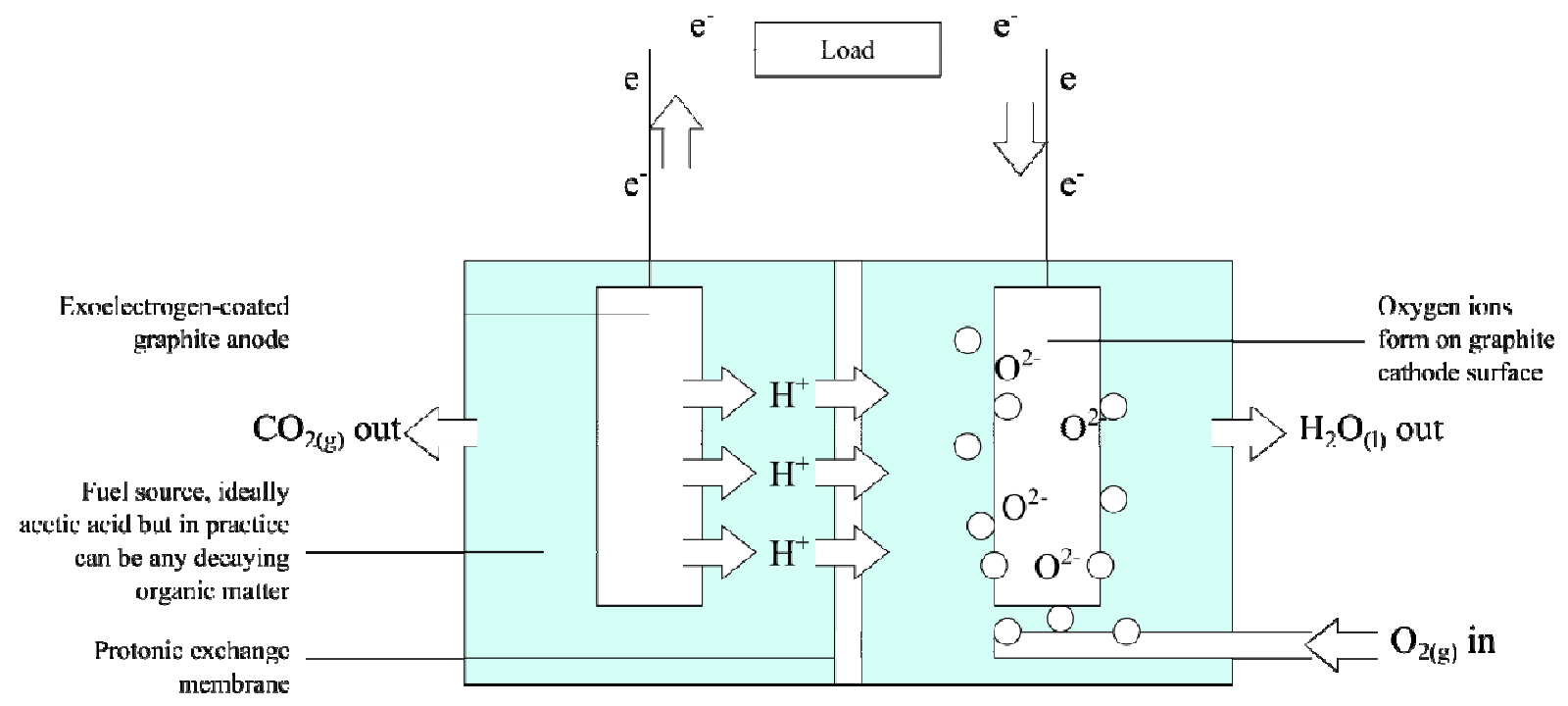

Fig. 1. A standard microbial fuel cell

A JAVA ${ }^{\mathrm{TM}}$ - based application has been developed to demonstrate the techniques described. This technology has been selected because of its robustness as a programming language, and its favorability in lending itself to community - based development.

\section{Uncertainty Budget Analysis}

Uncertainty budgets are created from the following relationships [8].

i. Random errors give rise to Type A uncertainties, which are quantified through the use of statistics. The Type A uncertainty is calculated by determining the sample standard deviation of the set of data acquired through measurement. The following equation is used to determine the Type A uncertainty contribution, also referred to as the standard uncertainty of the mean:

$$
u\left(x_{n}\right)=\frac{s}{\sqrt{n}}
$$

Where $u\left(x_{n}\right)$ is the standard uncertainty of the mean, $\mathrm{s}$ is the sample standard deviation and $\mathrm{n}$ is the number of measurements recorded.

ii. Systematic errors, which give rise to Type B uncertainties, are obtained from scientific literature on the measurement process and previous calibration certificates of instruments employed.

iii. The sensitivity coefficients are either calculated, or obtained from suitable literature for each error source identified. The sensitivity coefficient for the $\mathrm{n}^{\text {th }}$ measurement may be evaluated by the following equation:

$$
c_{n}=\frac{\partial y}{\partial x_{n}}
$$

Where $\mathrm{y}$ is the derived quantity and $\mathrm{c}_{\mathrm{n}}$ and $\mathrm{x}_{\mathrm{n}}$ are the $\mathrm{n}^{\text {th }}$ sensitivity coefficient and measured quantity respectively.

iv. $\quad \mathrm{A}^{2}$ suitable probability distribution must be selected for the uncertainty sources. The three distributions used include Rectangular (I), Triangular (II) and Normal (III). Each distribution has a unique divisor that must be included in the uncertainty budget. The table below summarizes the divisors:

\footnotetext{
${ }^{2}$ Other probability distributions would have to be included for Electro-Impedance Spectroscopy
} 
Table 1. Probability Distributions Utilized

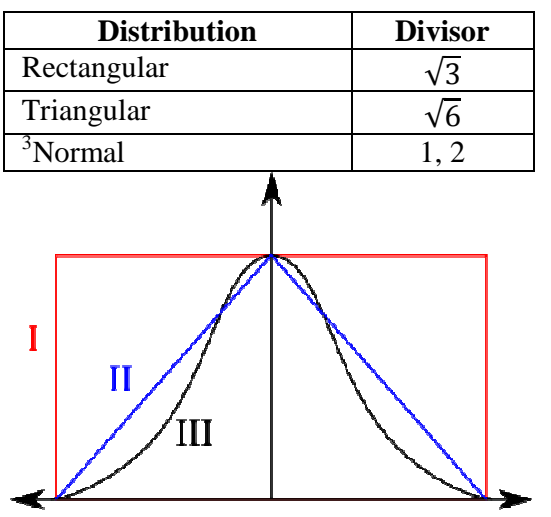

Fig. 2. Probability Distributions

v. The uncertainty associated with any function may be expressed by the following mathematical relationship:

$u(y)=\sqrt{\frac{c_{1}^{2} u^{2}\left(x_{1}\right)}{n_{1}^{2}}+\cdots+\frac{c_{i}^{2} u^{2}\left(x_{i}\right)}{n_{i}^{2}}}$

Where $u(y)$ is the combined uncertainty of the derived quantity and $\mathrm{u}\left(\mathrm{x}_{\mathrm{i}}\right), \mathrm{c}_{\mathrm{i}}$ and $\mathrm{n}_{\mathrm{i}}$ are the $i^{\text {th }}{ }^{4}$ uncertainty source, sensitivity coefficient and divisor respectively.

vi. The final step in the uncertainty calculation involves the determination of the expanded uncertainty. The expanded uncertainty is the product of the combined uncertainty and a coverage factor based on the effective number of degrees of freedom and confidence interval. The following equation is used to calculate the effective degrees of freedom:

$$
v_{e f f}=\frac{u^{4}(y)}{\sum_{i=1}^{n} \frac{c_{i}^{4} u^{4}\left(x_{i}\right)}{v_{i}}}
$$

Where $v_{\text {eff }}$ is the effective degrees of freedom, $\mathrm{u}(\mathrm{y})$ is the uncertainty of the derived quantity, $c_{i}$ is the sensitivity coefficient, $\mathrm{u}\left(\mathrm{x}_{\mathrm{i}}\right)$ and $\mathrm{v}_{\mathrm{i}}$ are the uncertainty and degrees of freedom for the $i^{\text {th }}$ physical quantity.

The degrees of freedom for Type A uncertainties will be equivalent to the

\footnotetext{
${ }^{3}$ Normal distributions have divisors of 1 or 2 depending on the whether the uncertainty is Type A or Type B respectively.

${ }^{4}$ This uncertainty source may be Type A or B
}

number of measurements used to evaluate the said Type A uncertainty.

Type B uncertainty contributions will typically have infinite degrees of freedom unless specified by ${ }^{5}$ relevant scientific literature. In cases where the degrees of freedom are infinite, the uncertainty contribution with respect to that term is zero.

The effective degrees of freedom should typically be a large number. The degrees of freedom, along with a desired confidence interval are then used with student's Ttables to obtain a coverage factor $\mathrm{k}$; $\mathrm{k}$ should ideally be between 2 and 1.96 . There are instances where this may not be possible - typically when the number of measurements used to evaluate the Type A uncertainty is small (n.b. this is sometimes unavoidable, especially when measurements are complex and manually performed).

Table 2. A generic uncertainty budget

\begin{tabular}{|l|c|}
\hline $\begin{array}{c}\text { Uncertainty } \\
\text { Source }\end{array}$ & Uncertainty Value \\
\hline Type $\mathrm{A}_{1}$ & $\frac{c_{1} u\left(x_{1}\right)}{n_{1}}$ \\
\hline Type $\mathrm{B}_{2}$ & $\frac{c_{2} u\left(x_{2}\right)}{n_{2}}$ \\
\hline$\cdot$ & $\cdot$ \\
\hline. & $\frac{c_{i} u\left(x_{i}\right)}{n_{i}}$ \\
\hline Type $\mathrm{B}_{\mathrm{i}}$ & $u(y)=\sqrt{\sum_{i=1}^{n} \frac{c_{i}^{2} u^{2}\left(x_{i}\right)}{n_{i}^{2}}}$ \\
\hline $\begin{array}{l}\text { Combined } \\
\text { Uncertainty }\end{array}$ & $u_{\exp }=k \times u(y)$ \\
\hline $\begin{array}{l}\text { Expanded } \\
\text { Uncertainty }\end{array}$ & \\
\hline
\end{tabular}

\section{Methodology}

The uncertainty in the temperature measurement was evaluated using a JAVA-based desktop application developed at the Physics Department, University of the West Indies, St. Augustine Campus. The uncertainty in temperature measurements was selected for evaluation because of the temperature

\footnotetext{
${ }^{5}$ Relevant literature refers to internationally accepted metrology publications from organizations such as UKAS, A2LA, NIST, OIML and other equivalent accrediting organizations
} 
dependant nature of the maximum potential of all fuel cells based on the Nernst equation.

The steps used to build the uncertainty budget included:

i. Identification of the mathematical relationship that related the measured and derived physical quantities. This would take the form of a physical law (such as Newton's $2^{\text {nd }}$ Law of motion $\left.F=m . a\right)$. In the case of temperature measurement, the following relationship applies:

$$
T_{\text {true }}=T_{\text {measured }}-\sum_{i=1}^{n} \delta t_{i}
$$

Where $\mathrm{T}_{\text {true }}=$ true temperature, $\mathrm{T}_{\text {measured }}=$ measured temperature and $\delta \mathrm{t}_{\mathrm{i}}=\mathrm{i}^{\text {th }}$ error in temperature measurement.

ii. For the given mathematical relationship, the variables and constants were identified. The sensitivity coefficients of variables were determined by partial integration of each independent variable with respect to the dependent variable.

iii. The calibration certificates for measuring instruments were reviewed to evaluate the instruments' uncertainties, coverage factors and drift between calibrations.

iv. The resolutions of instruments were also documented as this would give rise to rounding errors.

v. All error sources were tabulated as shown in table 2 .

vi. The combined and expanded uncertainties were then evaluated using the equations stated in the preceding section.

vii. In order to determine the largest contributor to the expanded uncertainty, the relative uncertainty was determined. This is calculated using the following relationship:

$$
u_{r e l}=\frac{u_{i}}{u_{e x p}}
$$

Where $\mathrm{u}_{\mathrm{rel}}=$ relative uncertainty and $\mathrm{u}_{\mathrm{i}}$ is the uncertainty contribution of the $i^{\text {th }}$ error source.

viii. The largest contributor to the expanded temperature uncertainty was identified.

The uncertainty budget was based on temperature data recorded using an Isotech K-type Semi-Precious Resistance Thermocouple with Hart digital temperature readout. The temperatures recorded were based on a Gallium slim fixed point cell. This data set was used to evaluate the Type A uncertainty in the thermocouple. The uncertainty and drift of the device were based on calibration certificates generated from ISO/IEC 17025:2005 accredited calibration laboratories.

The following table describes the uncertainty sources:

Table 3. Uncertainty sources

\begin{tabular}{|l|l|}
\hline \multicolumn{1}{|c|}{$\begin{array}{c}\text { Uncertainty } \\
\text { Source }\end{array}$} & \multicolumn{1}{c|}{ Description } \\
\hline Repeatability & $\begin{array}{l}\text { Standard deviation of recorded } \\
\text { data divided by the root of the } \\
\text { sample size }\end{array}$ \\
\hline $\begin{array}{l}\text { Thermometer } \\
\text { Uncertainty }\end{array}$ & $\begin{array}{l}\text { Uncertainty value quoted on } \\
\text { calibration certificate }\end{array}$ \\
\hline $\begin{array}{l}\text { Uncorrected } \\
\text { Error }\end{array}$ & $\begin{array}{l}\text { Absolute value of change } \\
\text { between temperature of } \\
\text { instrument and reference, based } \\
\text { on calibration certificate }\end{array}$ \\
\hline $\begin{array}{l}\text { Thermometer } \\
\text { Drift }\end{array}$ & $\begin{array}{l}\text { Change in temperature between } \\
\text { successive calibration certificates } \\
\text { at a specified set point }\end{array}$ \\
\hline $\begin{array}{l}\text { Thermometer } \\
\text { Resolution }\end{array}$ & $\begin{array}{l}\text { Based on the readability of the } \\
\text { thermometer }\end{array}$ \\
\hline $\begin{array}{l}\text { Zone } \\
\text { Differential }\end{array}$ & $\begin{array}{l}\text { This was calculated as the change } \\
\text { in the maximum and minimum } \\
\text { temperature recorded in a data set } \\
\text { divided by two }\end{array}$ \\
\hline
\end{tabular}

\section{Results and Discussion}

The following values were used in the uncertainty application based the temperature recording instrument specified earlier.

Table 4. Parameters used in Uncertainty Application

\begin{tabular}{|l|c|}
\hline \multicolumn{1}{|c|}{ Source } & $\begin{array}{c}\text { Input Value/ } \\
{ }^{\circ} \mathbf{C}\end{array}$ \\
\hline Repeatability & $1.1169 \times 10^{-3}$ \\
\hline Thermometer Uncertainty & 0.003 \\
\hline Uncorrected Error & 0 \\
\hline Thermometer Drift & 0.0005 \\
\hline Resolution of Thermometer & 0.001 \\
\hline
\end{tabular}

These values yielded the following uncertainty contributions based on the software. Items 1-6 represent the uncertainty contributors and items 7-11 represent other descriptive statistics. The value of highest interest is the expanded uncertainty, item 8 . Based on the software this value was $\pm 0.00381{ }^{\circ} \mathrm{C}$.

1. Repeatability: $0.00014{ }^{\circ} \mathrm{C}$

2. Uncertainty: $0.00150{ }^{\circ} \mathrm{C}$ 
3. Uncorrected Error: $0.00000{ }^{\circ} \mathrm{C}$

4. Drift: $0.00029^{\circ} \mathrm{C}$

5. Resolution: $0.00029^{\circ} \mathrm{C}$

6. Zone Differential: $0.00115^{\circ} \mathrm{C}$

7. Combined Uncertainty: $0.00194{ }^{\circ} \mathrm{C}$

8. Expanded Uncertainty: $0.00381{ }^{\circ} \mathrm{C}$

9. Degrees of Freedom: 296045

10. Coverage Factor: 1.96

11. Sample Size: 60

The graphical representation shows the relative uncertainties of the individual contributors.

\section{Relative Uncertainties vs. Contributor}

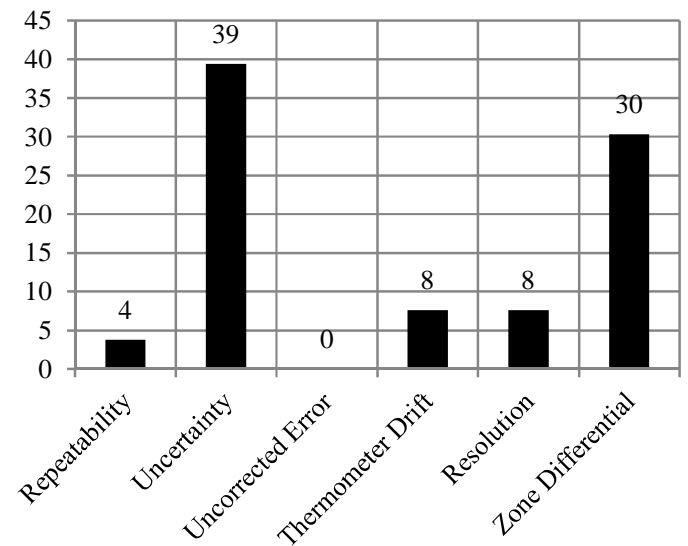

Fig. 3. Graph showing relative uncertainties

Typically, if the expanded uncertainty is low (i.e. less than or equal four times the instrument's resolution) then no process optimization is necessary. However, in instances where the expanded uncertainty exceeds four times the reference's resolution the uncertainty contributors with the highest relative uncertainties should be investigated first.

This strategy can also be employed in the measurement of output voltages, and resistance loads used in the assessment of renewable energy technology parameters, with the ultimate goal of quantifying risk associated with the performance of renewable technologies.

\section{Conclusion}

Industrial practices for estimating uncertainty in temperature measurement were explored. Temperature measurement was selected, not only because of its simplistic nature, but because of its fundamental importance in the determination of the theoretical open circuit voltage achievable by all fuel cell technologies. Further studies are required to evaluate uncertainties in the open circuit voltages, power densities, fuel cell efficiency and current densities of fuel cell systems.

\section{Acknowledgements}

The authors would like to thank the Caribbean Industrial Research Institute's Calibration Laboratory, IAS Accreditation Number CL-134 and Mr. Liaquat Ali-Shah (Chief Executive Officer, Caribbean Industrial Research Institute) for providing technical support and necessary instruments.

\section{References}

[1] B. E. Logan, Microbial fuel cells. WileyInterscience, 2008, p. 200.

[2] J. (MIT E. R. Craven, "Microbial Fuel Cells: A Potential Platform for the New Decade," MIT Entrepreneurship Review, 2010. [Online]. Available: http://miter.mit.edu/article/microbialfuel-cells-potential-platform-new-decade.

[Accessed: 16-Oct-2011].

[3] U. Schröder, "Anodic electron transfer mechanisms in microbial fuel cells and their energy efficiency.," Physical chemistry chemical physics: PCCP, vol. 9, no. 21, pp. 2619-29, Jun. 2007.

[4] B. E. Logan, "Scaling up microbial fuel cells and other bioelectrochemical systems.," Applied microbiology and biotechnology, vol. 85, no. 6, pp. 1665-71, Feb. 2010.

[5] BIPM, Evaluation of measurement data - Guide to the expression of uncertainty in measurement. 2008.

[6] EAL Task Force (European co-operation for Accreditation), "Expression of the Uncertainty of Measurement in Calibration," European cooperation for Accreditation, 1999.

[7] B. E. Logan et al., "Microbial Fuel Cells: Methodology and Technology," American Chemical Society, vol. 40, no. 17, pp. 5181-5192, 2006.

[8] L. Kirkup and B. Frenkel, An Introduction to Uncertainty in Measurement, 1st ed. Cambridge: Cambridge University Press, 2006, p. 225. 